\title{
Asymmetric $\alpha$-Allylation of Aldehydes with Simple Allylic Alcohols
}

Metal-Catalyzed

Asymmetric

Synthesis and

Stereoselective

Reactions

Key words

allylation

chiral

counteranions

palladium

SYNFACTuth

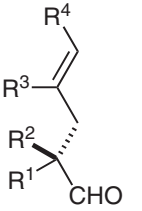

up to $98 \%$ yield er up to 99.8:0.2

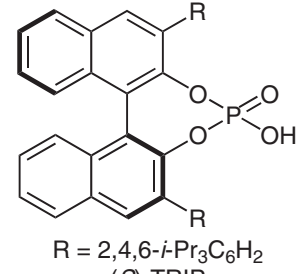

(S)-TRIP

Proposed mechanism:<smiles>C=CCC(C)(C=O)c1ccccc1</smiles>
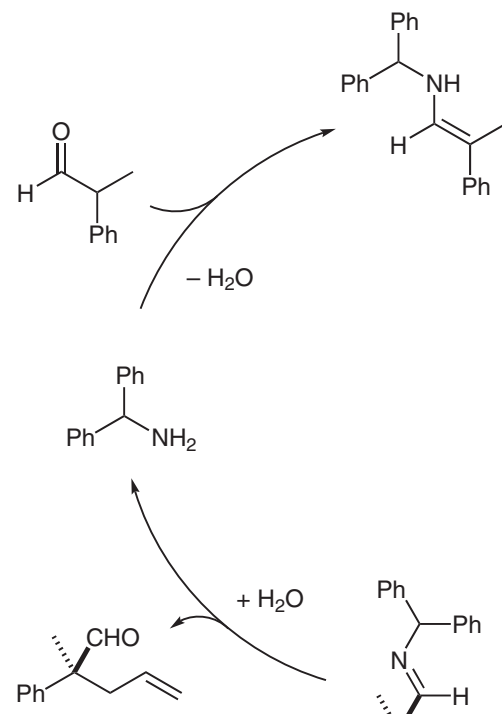

high er

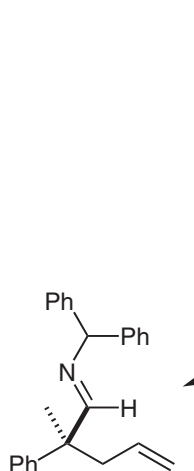

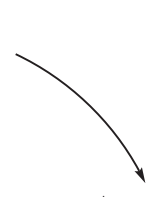

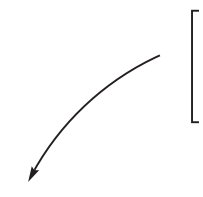

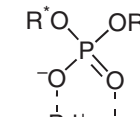
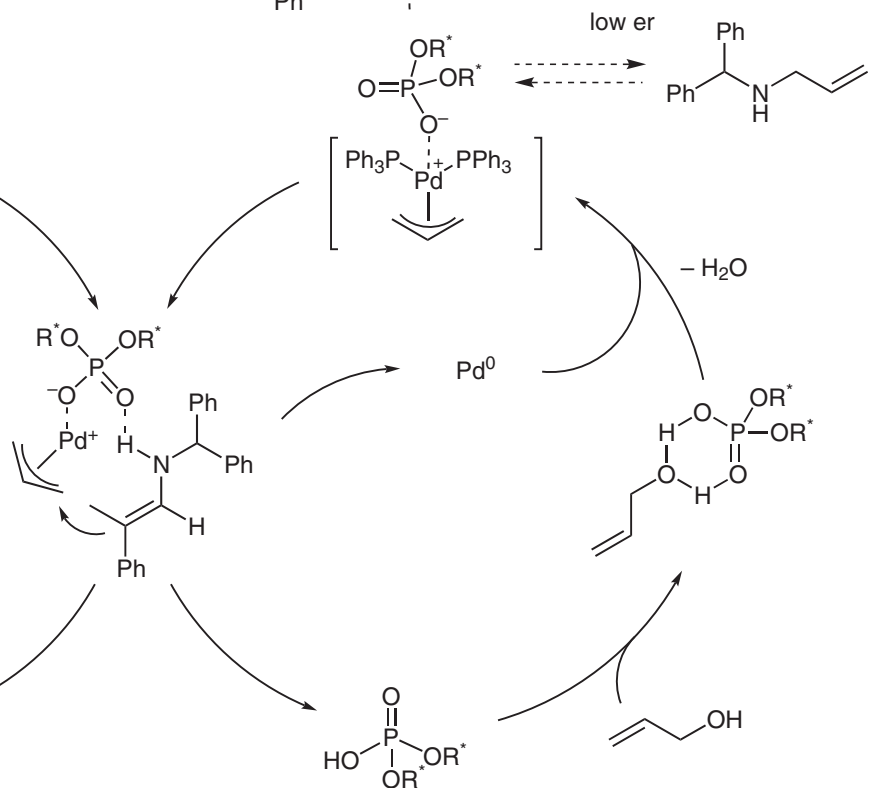

Significance: List and co-workers developed an enantioselective direct $\alpha$-allylation of $\alpha$-branched aldehydes with allylic alcohols generating products with all-carbon quaternary stereogenic centers in high yields and excellent enantioselectivities. The general reaction scale for this transformation is $0.2 \mathrm{mmol}$.
Comment: It is suggested that the high enantioselectivity for the described transformation arises from an asymmetric counteranion-directed catalysis (ACDC) complex - three different catalytic species are involved: $\left[\mathrm{Pd}\left(\mathrm{PPh}_{3}\right)_{4}\right]$, the chiral Brønsted acid TRIP, and benzhydryl amine.

SYNFACTS Contributors: Mark Lautens, Patrick T. Franke 